\title{
УДК $332.142+338.246 .2$
}

\section{Современные финансовые технологии торгово-логистической компании}

\author{
Д-р экон. наук Василенок В.Л. fem1421@yandex.ru \\ Университет ИТМО \\ 197101, Россия, Санкт-Петербург, Кронверкский пр.,49 \\ Гуменюк A.A. gumenyuk_nastasya@mail.ru \\ Санкт-Петербургский государственный университет, \\ Санкт-Петербург, ул. Чайковского, д. 62.
}

\begin{abstract}
Финансовые технологии - пока еще малоизученная экономическая категория, хотя первые их разновидности появились несколько столетий назад. С усложнением экономических отношений, увеличением возможностей перераспределения финансовых средств появляются и новые возможности их использования. Деривативы позволяют не только использовать новые варианты инвестирования средств, но и управлять рисками, что наиболее важно с точки зрения рационального инвестирования. Принимая решения, направленные на реализацию своих целей, финансовые институты одновременно воздействуют на денежный рынок, валютный рынок, рынок ценных бумаг и их производных инструментов. Российский финансовый рынок, к сожсалению, отстает от развитых стран по уровню развития инновационных инструментов и технологий. Однако, это создает дополнительные побудительные мотивы для российских специалистов к тому, чтобы обратить внимание на современные финансовые технологии, которые способны сыграть значительную роль в развитии российского финансового рынка и экономики в целом. Использование различных инструментов постоянно расииряется и включает как традиционные приемы, так и новейиие методы. От того, насколько правильно будет выбран тот или иной инструмент, будет зависеть, в конечном счете, эффективность деятельности компании в целом.

Ключевые слова: факторинг, хеджирование, страхование валютных рисков, финансовые потоки.
\end{abstract}

DOI: $10.17586 / 2310-1172-2017-10-3-40-45$

\section{Modern financial technologies of a trading and logistic company}

\author{
D.Sc., professor Vasilenok V.L. fem1421@yandex.ru \\ ITMO University \\ 49, Kronverksky pr. St. Petersburg, 197101, Russia \\ Gumenyuk A.A. gumenyuk_nastasya@mail.ru \\ St. Petersburg State University, St. Petersburg, ul. Tchaikovsky, 62.
}

Financial technologies are still a little-studied economic category, although their first varieties appeared several centuries ago. With the increasing complexity of economic relations, the increased opportunities for redistribution of financial resources, and new opportunities for their use. Derivatives allow not only to use new options for investing funds, but also manage risks, which is most important from the point of view of rational investment. Making decisions aimed at achieving its goals, financial institutions simultaneously influence the money market, the foreign exchange market, the securities market and their derivatives. The Russian financial market, unfortunately, lags behind developed countries in terms of the level of development of innovative tools and technologies. Nevertheless, this creates additional incentives for Russian specialists to pay attention to modern financial technologies that can play an important role in the development of the Russian financial market and the economy as a whole. The use of various tools is constantly expanding and includes both traditional techniques and the latest methods. On the basis of how correctly this or that instrument will be chosen, the effectiveness of the company's performance as a whole will depend, ultimately.

Keywords: factoring, hedging, currency risk insurance, financial flows.

Основу финансовых технологий составляют разнообразные виды сделок и операций, осуществляемых предприятием на рынке. В процессе разработки эффективной стратегии, способствующей повышению качества управления финансовой деятельностью, основной задачей является расширение использования современных видов сделок и операций, адаптированных под реалии и соответствующие целям и планам организации. Без 
понимания рынка, своих возможностей и финансовой грамотности невозможно выдержать острую конкурентную борьбу.

Рассмотрим возможные современные финансовые технологии на примере крупного игрока торговологистического рынка. Компания «Ингридиентс», основным направлением деятельности которой является торговля пищевыми ингредиентами и оказание торгово-логистических услуг уровня 4PL.

Основные покупатели-мультинациональные компании, федеральные компании, действующих контрактов порядка 120 шт. Основные поставщики - иностранные компании, Российские компании-гиганты. Действующих контрактов порядка 100 шт.

Основные направления закупок и реализации:

- томатная паста и соковые концентраты,

- молочные продукты (масло сливочное, масло кокосовое, масло пальмоядровое, ЗМЖ, рафинированное/дезодорированное масло)

- соль (фторированная, морская, нитритная)

- прочие пищевые ингредиенты (крахмалы, глутамат натрия, мука, сахар, прочее)

Показатели выручки в динамике:

в 2014 г. - 0,84 млрд. руб.

в 2015 г. - 1,7 млрд. руб.

в 2016 г. - 2,6 млрд. руб.

план на 2017 г. - 5,9 млрд. руб.

В перспективе - расширение ассортимента и объемов реализации, расширение пула постоянно действующих клиентов, в т.ч. укрепление связей с имеющимися компаниями и с основными контрагентами.

Цель-стать значимыми и эксклюзивными поставщиками для клиентов на рынке РФ, построить цивилизованную торгово-логистическую структуру в сегменте В2В (поставки сырья пищевым производствам и стать одним из лидеров в данном сегменте на рынке России).

Основные источники финансирования - выручка и кредитные займы. В разрезе процентное соотношение составляет $23 \%$ и 77 \%. В большинстве своем - долгосрочные кредиты (от 2-х до 5-ти лет).

Основные финансовые потоки направлены на укрепление партнерских отношений с действующей базой клиентов путем расширения ассортимента поставляемой продукции. Задача - стать единственным поставщиком пищевых ингредиентов для клиента. Для ее осуществления необходима определенное финансовое подспорье и финансовые технологии, актуальные в определенный момент времени.

Финансовые технологии - комбинирование финансовых инструментов с различными параметрами риска и доходности для реализации инвестиционной стратегии бизнеса.

Финансовая инновация - это новые финансовые инструменты и финансовые технологии. Финансовые инструменты делятся на:

- концептуальные средства - понятие и концепции, которые лежат в основе финансов как неформальной дисциплины;

- физические средства - инструменты и процессы, которые можно использовать для достижения какойнибудь конкретной цели

Финансовый риск - это вероятность наступления ущерба в результате проведения каких-либо операций в финансово-кредитной и биржевой сферах, совершения операций с фондовыми ценностями, т.е. риск, вытекающий из природы этих операций.

К финансовым рискам можно также отнести риск наступления косвенного (побочного) финансового ущерба (неполучения/ недополучения прибыли) в результате наступления страхового события - остановки производства (торговли) из-за утраты, повреждения застрахованного имущества. Этот риск угрожает, прежде всего, производственным предприятиям [1]

Поскольку компания является мощным игроком на рынке, имеет своей целью активное завоевание новых горизонтов-необходимо отслеживать основные тенденции и иметь достаточные ресурсы для реакции. Порой своевременная реакция и обеспечение поставки нашему клиенту эксклюзивного продукта - причина закрепления своих позиций и конкурентного преимущества.

Для этого необходимо эффективное использование определенных финансовых технологий, позволяющих облегчить цепочку поставки и избежать определенных рисков, которые могут возникнуть при работе с иностранными поставщиками на различных условиях. К ним можно отнести:

Операчии страхования финансовых рисков. Такие операции предприятие имеет возможность проводить на всех без исключения видах финансового рынка. На этом рынке основными операциями данной группы являются диверсификация финансовых инструментов, хеджирование ценовых (курсовых) рисков, а также прямое страхование имущества (активов) и ответственности. 
Операции по рефинансированию дебиторской задолженности. Целью этих операций является ускоренный перевод дебиторской задолженности в другие формы оборотных активов предприятия: денежные средства и высоколиквидные краткосрочные ценные бумаги.

Основными формами рефинансирования дебиторской задолженности, используемыми в настоящее время, являются:

- факторинг;

- учет векселей, выданных покупателями продукции;

- форфейтинг.

Для нашей компании основам инструментов является факторинг.

Факторинг представляет собой финансовую операцию, заключающуюся в уступке предприятиемпродавцом права получения денежных средств по платежным документам за поставленную продукцию в пользу банка или специализированной компании - «фактор компании», которые принимают на себя все кредитные риски по инкассации долга. За осуществление такой операции банк (фактор-компания) взимают с предприятияпродавца определенную комиссионную плату в процентах к сумме платежа. Ставки комиссионной платы дифференцируются с учетом уровня платежеспособности покупателя продукции и предусмотренных сроков ее оплаты. Кроме того, при проведении такой операции банк (фактор-компания) в срок до трех дней осуществляет кредитование предприятия-продавца в форме предварительной оплаты долговых требований по платежным документам (обычно в размере от 70 до 90\% суммы долга в зависимости от фактора риска). Остальные 10-30\% суммы долга временно депонируются банком в форме страхового резерва при его непогашении покупателем (эта депонированная часть долга возвращается предприятию-продавцу после полного погашения суммы долга покупателем).

Главным преимуществ факторинга считается снижение рисков. Снижается риск ликвидности, потому что после отгрузки товара или предоставления услуг предприятие получает средства, которые можно пустить в оборот. Также снижаются валютные риски, особенно это актуально предприятиям, которые работают с иностранными и национальными деньгами. Некоторые виды факторинга помогают избежать риска неуплаты, который полностью возлагается на банк, предоставляющий услугу факторинга [2]. Следующим существенным преимуществом факторинга является освобождение от потребности отслеживания долгов. В интересах фактора получить свои денежные средства обратно, поэтому его сотрудники отслеживают погашение долгов и связываются с должником, пропустившим срок оплаты. Факторинг не требует залога. К тому же фактор проводит проверку не так тщательно, как финансово-кредитное учреждение при выдаче ссуды на развитие бизнеса. Недостатки факторинга, прежде всего, заключаются в его дороговизне. Фактор взимает проценты за обеспечение отгрузки и доставки товара, комиссию за услугу факторинга, сбор всех нужных документов, которые он ведет для своего клиента-предприятия. В итоге получается, что выплаты по кредиту меньше.

К финансовому методу управления валютными рисками можно отнести хеджирование - метод снижения рисков при помощи инструментов финансового рынка. Предприятие может принять решение хеджировать все риски, какую-то их часть либо отказаться от него вовсе.

Хеджирование как метод управления валютными рисками относится к внешним методам управления, т.е. при хеджировании предприятие прибегает к услугам сторонних компаний (банков, финансовых компаний, участников биржевой торговли.

Валютный опцион-сделка, по которой покупатель получает право купить или продать определенный объем валюты по заранее зафиксированной цене в день истечения опционного контракта.

В зависимости от того, какое право желает приобрести покупатель опциона-купить или продать валютуони подразделяются на опционы «колл» и «пут». Первый дает право покупателю купить валюту по определенной цене, а второй-продать. В обоих случаях покупатель опциона приобретает только право, но не обязанность исполнения опциона, в то время как у продавца при совершении опционной сделки возникает обязанность ее исполнить. Это дает преимущество покупателю опциона. Данное преимущество покупатель обязан оплатить в виде опционной премии. Опционную премию можно сравнить со страховой премией, которая уплачивается при страховании имущества, однако в данном случае страховым событием будет являться получение возможных убытков из-за колебания валютных курсов. [3]

Основная цель применения подобных инструментов - заранее зафиксировать валютную себестоимость импортного товара и учесть ее при формировании отпускных цен, тем самым сохранив свой маржинальный доход вне зависимости от валютных. Хеджирование валютных рисков позволяет сохранять и повышать конкурентоспособность в краткосрочном периоде, эффективно реагировать на изменение валютного курса.

Таким образом, эффективное использование всех вышеперечисленных методов позволяет снизить риски, быть более гибкими, активно реагировть на меняющиеся тенденции, что является несравненным конкурентным преимуществом, как и эффективная логистика, для построения которой существует свой набор финансовых инструментов. 
На данный момент политика крупнейших производителей товаров в области обеспечения своих логистических потребностей строится на принципах «диверсификации» - все объемы постаок делятся между 5-6 логистическими партнерами. В этом случае часть логистических функций - планирование, регулирование отношений с подрядчиками - осуществляется за счет ресурсов предприятия. Таким образом предприятия обеспечивают свою «логистическую безопасность». Если они хотя выиграть в конкурентной борьбе, необходимо делать акцент на мировые тенденции - «разделения труда» с целью оптимизации затрат. При работе с мультинациональными компаниями, на рынок которых ориентирована политика рассматриваемой компании, важно стать логистическим монополистом. В связи с чем - ключевое конкурентное преимущество- оказание сервиса уровня 4PL, включающий в себя полный цикл импортной и/или внутренней логистики, который можно представить следующим образом:

- поиск поставщика;

- организацию и управление закупками под производственный план клиента;

- импорт/экспорт, перевозку, страхование, экспедирование;

- управление и поддержание запасов на собственных складах;

- обработку и подготовку груза под требования клиента: качественный отбор, - переупаковка, маркировка;

- оперативную доставку по заказам клиента.

Основные преимущества 4PL подхода - в оптимизации расходов предприятия и повышение его эффективности за счет сокращения операционных затрат, трудовых ресурсов, оборотного и основного капитала. По некоторым исследованиям, интеграция технологий квалифицированного логистического провайдера в деятельность клиента, формирование общего информационного пространства способна сократить операционные затраты предприятия на 15\%, материальные ресурсы - на $30 \%$. Минимизация складских запасов, сокращение ресурсных затрат на обеспечение логистического процесса способствует сокращению цикла «заказ-деньги». Отсутствие необходимости в содержании собственных материальных активов для обеспечения логистических процессов снижает уровень вложений в основной капитал предприятия. Таким надежным логистическим партнером, так называемой, «мощной опорой» готово рассматриваемое предприятие.

Регулирование взаимоотношений с поставщиками, условий поставок и платежей, обеспечение их ритмичности - все это типичные задачи «потокового» планирования в ЛС. Организация закупок и продаж, координирование складских операций и транспортировки товаров также являются типичными «потоковыми» задачами.

В каждом отдельном случае создание деловых схем предполагает выбор оптимальных организационноправовых форм. Нередко в бизнес-схемах используются комбинированные корпоративные конструкции, включающие несколько юридических лиц различных типов. Большая группа схем основана на включении в цепочку предприятий, входящих в состав ЛС тех, которые пользуются теми или иными налоговыми льготами. Основой управления финансовыми потоками в ЛС служит логистическое бюджетирование, цель которого обеспечить оптимальные возможности для успешной производственно-снабженческо-сбытовой деятельности, получить необходимые для этого финансовые средства и в конечном итоге достигнуть прибыльности для организации. Иначе говоря, логистическое бюджетирование представляет собой процесс разработки совокупности плановых (нормативных) показателей для обеспечения развития системы необходимыми материально-финансовыми ресурсами, координации и контроля за ходом реализации планов и повышения эффективности производственно-сбытовой деятельности в будущем периоде.

Логистический бюджет - комплексная система финансовых составляющих, разрабатываемая в рамках одного года, отражающая объемы и сроки обеспечения организации необходимыми материально-финансовыми ресурсами на всех участках логистической цепи. Система логистического бюджетирования помогает установить лимиты затрат ресурсов и нормативы рентабельности или эффективности по всей логистической цепочке и отдельным структурным подразделениям. Превышение установленных лимитов сигнализирует о необходимости разобраться в положении дел на конкретном участке и определить пути решения имеющихся проблем, вызванных недостатком финансовых и материальных ресурсов.

Процедура формирования бюджета логистической системы представляет собой целостную систему сбора и обработки информации, получаемой из внутренней и внешней среды, расчетов основных и вспомогательных показателей экономического состояния логистической системы и контроля за их выполнением на основе экономико-математических моделей и технологий на всех этапах реализации логистического бюджета.

Сформированный бюджет позволяет:

- организовывать и контролировать финансовые потоки логистической системы;

- эффективно управлять затратами на закупку материальных ресурсов, производство, сбыт и сервис, регулировать уровень оборотных средств логистической системы (в том числе запасов), дебиторской и кредиторской задолженностей;

• оптимизировать налогообложение логистической системы; 
- управлять документооборотом внутри логистической системы;

- осуществлять контроль над эффективной работой подразделений логистической системы и их руководителей на всех стадиях реализации бюджета.

Управление финансовыми потоками на базе логистического бюджетирования позволяет: адекватно планировать уровень финансового обеспечения потоковых процессов на промышленных предприятиях; с достаточной степенью достоверности определять ожидаемый объем прибыли как на отдельных функциональных участках логистической системы, так и в целом по предприятию; прогнозировать изменения прибыли и рентабельности в зависимости от изменения объема производства, цен на продукцию, величины переменных или постоянных затрат; повысить уровень анализа фактического положения предприятия; принимать эффективные управленческие решения о развитии деловой активности и совершенствовании процесса производства; максимизировать прибыль предприятия. Однако с появлением новых инструментов для управления рисками управление денежными средствами становится более сложным и в то же время более совершенным.

Финансовые потоки в логистической системе неоднородны по составу, направлениям движения, назначению и ряду других признаков. Потребность в определении наиболее эффективных способов управления логистическими финансовыми потоками обуславливает необходимость их классификации.

Один из вариантов классификации финансовых потоков в логистике, позволяющий системно представить их многообразие.

Картина финансовых потоков в ЛС используется для решения многих управленческих задач - от оптимизации организационной структуры и деловых связей до разработки проекта ЛС и ее комплексной оптимизации.

Особенность потоковых методов состоит в необходимости рассматривать финансовые потоки ЛС во взаимосвязи с производством, транспортировкой, снабжением, сбытом и другими хозяйственными функциями предприятия, а также составляющими ЛС. Хозяйственные процессы представляются как потоки товарных, финансовых и других материальных и нематериальных ресурсов из серии коммерческих операций. В потоковые схемы могут быть включены и каналы передачи информации, документооборот компании и управленческие решения. [9]

Оптовая продажа товаров может осуществляться в двух формах - транзитом, когда оптовое предприятие продает товары без завоза их на свои склады, и продажей товаров со своих складов.

Транзитные отгрузки позволяют снижать издержки, что благоприятно сказывается на финкосте, как следствие-повышение маржинальности поставляемого продукта. В связи с этим предпочтительно выстраивать грамотные схемы отгрузок с транзитных складов.

\section{Литература}

1. Аюпов А.А. Производные финансовые инструменты: обращение и управление / А.А. Аюпов. - Тольятти: ТГУ, 2012. $-202 \mathrm{c}$.

2. Ивасенко А.Г., Ивасенко А.Г., Казаков В.В., Казаков В.В., Никонова Я.И., Никонова Я.И. Инновации на финансовых рынках: теоретические и методологические аспекты // Международный журнал экспериментального образования. 2015. № 2-2. С. 269-270

3. Полтева Т.В., Мингалёв Н.В. Анализ финансовых инструментов инвестирования: соотношение риска и доходности // Карельский научный журнал. 2013. № 4. С.33-36.

4. Ефимов А.А. Финансовые методы хеджирования валютных рисков на промышленных предприятиях // Вестник Удмуртского университета. 2011. № 3

5. Макеева Ф.С. «Комплексный анализ хозяйственной деятельности предприятия», 2010

6. Парушина Н., Сучкова Н. Финансовое состояние организаций. Системный подход к анализу и управлению. Теория, методика и практика: Монография / LAP LAMBERT AcademicPublishing, Германия. 2011. 260 c.

7. Современные финансовые рынки. Монография для магистрантов, обучающихся по программам направления «Финансы и кредит». Под ред. Иванова В.В. «Издательство «Проспект», 29 июл. 2014 г. С. 537

8. Парфенов А.В. Методология формирования логистической системы управления потоковыми процессами в транзитивной экономике. СПб.: СПбГУЭФ, 2001. - 183 с.

9. Акбердин Р.З. Экономическое обеспечение логистики и финансовые потоки: Учеб. пособие / ГУУ. М.: 2002.

10. Савкина Р.В. Планирование на предприятии; Дашков и Ко. -М.: 2012. -324 с

11. Джон К. Халл. Глава 26. Процентные деривативы: стандартные рыночные модели: Европейские свопционы // Опционы, фьючерсы и другие производные финансовые инструменты = Options, Futures and Other Derivatives. - 6-е изд. - М.: «Вильямс», 2007. - С. 1056. - ISBN 0-13-149908-4.

12. Иван Дарушин, Финансовый инжиниринг: инструменты и технологии. Монография. 2015 г. 


\section{References}

1. Ajupov A.A. Proizvodnye finansovye instrumenty: obrashhenie i upravlenie / A.A. Ajupov. - Tol'jatti: TGU, 2012. $202 \mathrm{p}$.

2. Ivasenko A.G., Ivasenko A.G., Kazakov V.V., Kazakov V.V., Nikonova Ja.I., Nikonova Ja.I. Innovacii na finansovyh rynkah: teoreticheskie i metodologicheskie aspekty // Mezhdunarodnyj zhurnal jeksperimental'nogo obrazovanija. 2015. № 2-2. P. 269-270

3. Polteva T.V., Mingaljov N.V. Analiz finansovyh instrumentov investirovanija: sootnoshenie riska i dohodnosti // Karel'skij nauchnyj zhurnal. 2013. № 4. P.33-36.

4. Efimov A.A. Finansovye metody hedzhirovanija valjutnyh riskov na promyshlennyh predprijatijah // Vestnik Udmurtskogo universiteta. 2011. № 3.

5. Makeeva F.S. «Kompleksnyj analiz hozjajstvennoj dejatel'nosti predprijatija», 2010

6. Parushina N., Suchkova N. Finansovoe sostojanie organizacij. Sistemnyj podhod k analizu i upravleniju. Teorija, metodika i praktika: Monografija / LAP LAMBERT AcademicPublishing, Germanija. 2011. 260 p.

7. Sovremennye finansovye rynki. Monografija dlja magistrantov, obuchajushhihsja po programmam napravlenija «Finansy i kredit». Pod red. Ivanova V.V. «Izdatel'stvo «Prospekt», 29 ijul. 2014 g. P. 537

8. Parfenov A.V. Metodologija formirovanija logisticheskoj sistemy upravlenija potokovymi processami $\mathrm{v}$ tranzitivnoj jekonomike. SPb.: SPbGUJeF, 2001.-183 p.

9. Akberdin R.Z. Jekonomicheskoe obespechenie logistiki i finansovye potoki: Ucheb. posobie / GUU. M.: 2002.

10. Savkina R.V. Planirovanie na predprijatii; Dashkov i Ko. -M.: 2012. -324 p

11. Dzhon K. Hall. Glava 26. Procentnye derivativy: standartnye rynochnye modeli: Evropejskie svopciony // Opciony, fjuchersy i drugie proizvodnye finansovye instrumenty = Options, Futures and Other Derivatives. - 6-e izd. - M.: «Vil'jams», 2007. - S. 1056. - ISBN 0-13-149908-4.

12. Ivan Darushin, Finansovyj inzhiniring: instrumenty i tehnologii. Monografija. 2015 g. 